\title{
Notes Towards a Typology of the DIY Institution: identifying do-it-yourself places of popular music preservation
}

Sarah Baker and Alison Huber

\begin{abstract}
This article presents some notes towards identifying what we have come to call 'DIY institutions': places of popular music preservation, archiving and display that exist outside the bounds of 'official' or 'national' projects of collection and heritage management. These projects emerge instead from within communities of music consumption, where groups of interested people have, to some degree, undertaken to 'do-it-themselves', creating places (physical and/or online) to store -- and, in some cases, display publicly -- the material history of music culture. In these places, people (largely volunteers) who are not expert in tasks associated with archiving, records management, preservation, or other elements involved in cultural heritage management, learn skills along the way as they work to collect, preserve and make public artefacts related to popular music culture. These places are, we argue, suggestive of broader desires from within communities of popular music consumption to preserve popular music heritage.
\end{abstract}

\section{Keywords}

institution - archive - museum - do-it-yourself/DIY - popular music - heritage preservation - sociality - affect - communities of practice 


\section{Notes Towards a Typology of the DIY Institution: identifying do-it-yourself places of popular music preservation}

\section{Introduction}

The existence of DIY institutions came to our attention during research for a project related to popular music and cultural memory in Australia and elsewhere in the world. ${ }^{i}$ In that project, we were concerned with the range of ways that popular music appears in cultural memory, across the spectrum of national and official discourse through to the small-scale and personal recollections of individuals. During the research, we became interested in national institutions that collect recordings and material artefacts related to popular music's history, and the parameters that constituted these collections. It was at this point that we began to notice a range of places that appeared to exist in parallel to these national institutions. These were places that were staffed principally by volunteers, operated only on donations and grants, and had similar aims in terms of the ways that they imagined and articulated the importance of cultural preservation, and the role of archives and museums in this task. We became intrigued by these places, and so paid visits to two in Australia: the Australian Country Music Hall of Fame (ACMHF) in Tamworth, New South Wales, and the Victorian Jazz Archive (VJA), in the outer suburbs of Melbourne, Victoria. Visits to overseas examples followed, and we began to note a series of common characteristics amongst these museums and archives that transgressed genre and nationality. It is with these similarities in mind that we work towards this 'typology'; that is, we begin to identify a series of commonalities that 
emerge across these institutions. We think these similarities are in turn suggestive of broader trends in the ways in which communities and individuals within those communities show interest in asserting ownership over and expertise in popular music's cultural history, which leads them to acts of preservation and display that contribute to our collective memory of these musics. Our intention here is not to create a typology in order to count institutions 'in' or 'out' of our analysis; rather we are working towards identifying a number of functions common to these institutions, while also recognising that they exist along a continuum that begins with the individual collector who seeks to establish a place to share his/her collection all the way through to the DIY institution that might have found enough funding for a few staff members and has become formalised to the extent that it is on the verge of official, national acceptance."i

It wouldn't be possible to list all the places that fit somewhere on the spectrum of the typology we outline here. Indeed, this project is one of ongoing discovery for us, as we continue to find institutions that articulate with this trend in grass-roots music preservation.ii In this article, we draw attention to only a small number of institutions we have visited as suggestive examples of the range of places of music history preservation and display that fall into the typology we establish here. ${ }^{\text {iv }}$ In addition to visiting each of the examples discussed, we conducted semi-structured ethnographic interviews with staff (primarily volunteers) at these institutions who contribute their labour to the preservation enterprise and we have also taken note of the range of printed and online material related to these places. 


\section{Naming the DIY institution}

Before we begin mapping out a possible typology, we first note the reasons for choosing the term 'DIY institution' to describe these places. The DIY ethic has long been an element of popular music culture and practice, holding particular potency in descriptions of (often politicised) practices related to punk and post-punk cultures. ${ }^{\vee}$ But DIY is also an identifiable trait in many other music cultures, including folk and country, and so seems a useful and recognisable signifier of the 'bottom-up' activities of the communitybased enterprises we are concerned with here, in which people have taken initiative and started these archival and museum collections themselves in ways that encapsulate the spirit of 'DIY'. This DIY spirit manifests itself differently in a variety of places that we would name as DIY institutions. Indeed, our research here belongs to a larger body of academic investigation into DIY or community-based practices of archiving and preservationism that extends beyond popular music. Literature that is particularly helpful in thinking through the different collecting and archival impulses at play in DIY institutions include that on DIY preservationism (Bennett 2009), community archiving (Flinn 2007), activist archiving (Collins 2012; Zinn 1970/1997) and popular archives (McKee 2011a; 2011b). What follows in this section, then, is an introduction to some of this work, and an attempt to broaden the specificity of the arguments presented in these different perspectives so as to include the DIY places we have visited, which are not necessarily represented in the existing accounts. What emerges, we think, is a continuum of DIY and community-based heritage practice around popular music preservation which is separate (but connected) to this research. 
Andy Bennett has recently noted a tendency towards 'DIY preservationism' (2009: 475) in popular music heritage practice. The 'DIY preservationist sensibility' (483) he identifies is primarily concerned with interested parties reclaiming "lost material", often for commercial exploitation (albeit on a small scale), in order to rewrite the conventional histories of rock culture. While our work here shares Bennett's concern with DIY in the context of popular music, the terrains of our interest are slightly different. The DIY institutions we have visited to date have not been focussed so much on 'conventions of taste and distinction' (483), or an urge to make good the inaccurate historical record by recovering forgotten works. Rather, the DIY institutions of our project often aim for an inclusive and thus 'taste-less' collection of material with limited or no interest in commercial opportunity. We can observe this desire in the mission statement of ARChive in New York City, an enormous archive of popular musics of the world that operates in part thanks to the donations of high-profile musician patrons, but otherwise runs on grant funding:

... the ARChive collects and preserves everything that's issued, hoping to define "what happened" in terms broader than those usually described by selectiveness or availability. Taste, quality, marketing, halls of fame, sales, stars and value are as alien to us as they are, well, to aliens. ('Why the ARC', n.d., our emphasis)

So while there is an urge in the institutions of our study to preserve material, and it is done by DIY practitioners, it has not so much of the 'preservationist' impulse; rather, it should be thought of as an indiscriminate desire to retain a material record of popular music's historical past, perhaps indicating a key difference between the cultural 
curation/connoisseurship described by Bennett and the cultural archiving of many of our DIY institutions.

While DIY examples of cultural preservation often operate in the shadows of official institutions and some people involved may well disagree with the ways in which formal institutions handle music in their collections (and vice versa), they are not, prima facie, anti-establishment or anarchic. Indeed, they often replicate the organisational structures of national institutions, giving people titles like 'General Manager', 'Collections Manager', 'Archivist', 'Curator', 'Data Entry Clerk', and so on. They frequently operate under and report to boards of management, follow expansive mission statements with aims that could be seen as comparable to national programs of collection and preservation, and strive to achieve industry standards in their practices. 'Institutionalisation' should not, therefore, be interpreted in negative terms, or as a constraint on the operation of the DIY spirit; rather the framework of the institution becomes, in many instances, enabling for the DIY enterprise. In relation to archives specifically, there has been increasing critical interest in such institutions that exist outside the purview of 'official' or governmental projects of national collecting, and these alternatives to 'official' institutions have been referred to in a variety of ways (Huvila, 2008; Moore \& Pell, 2010).

Perhaps the most influential of these conceptions is Andrew Flinn's identification of the 'community archive', or what he defines as 'the grassroots activities of documenting, recording and exploring community heritage in which community participation, control and ownership of the project is essential' (Flinn, 2007: 153). Flinn 
acknowledges the difficulties in defining community and so opts for a broad, yet focussed, definition with community referring to, 'a group who define themselves on the basis of locality, culture, faith, background, or other shared identity or interest' (2007: 153, orig. emph.). Although the community may not always understand their collective work as 'archiving', these 'independent' archives are made up of 'collections of material gathered primarily by members of a given community' (Stevens, Flinn \& Shepherd, 2010: 59). As such, they 'often attempt to actively transform and intervene in otherwise partial and unbalanced histories', thus 'contributing to a democratization of heritage and history making' (Flinn, 2010: 40). Many of the community archives which Flinn and others investigate under this nomenclature are concerned with documenting minority or marginal communities, and are forms of activism and ownership over a community's stories about their past (Flinn, Stevens \& Shepherd, 2009; Flinn, 2007).

Most recently, Jez Collins has drawn on Howard Zinn's (1970/1997) notion of 'activist archiving', arguing for the existence of such activist-based practices in popular music-related communities, particularly in instances which result in the creation of digital archives that document local and/or marginalised community's music scenes (Collins, 2012). Collins himself is an activist archivist having set up the online Birmingham Music Archive $^{\mathrm{vi}}$, and has links to many other grassroots organisations engaged in the construction of archives. We agree with Collins that it is certainly with an activist spirit that many of these 'community' archives, including those focused on music, are generated. However, in the case of our research to date, we don't wish to make such an explicit claim on 'activism' or overt politicality, and instead have observed everyday interventions by amateurs and enthusiasts keen to 'do archiving themselves' (hence our 
nomenclature, 'DIY'). In this sense, then, Collins's examples of 'activist archives' exist on a continuum of community-based modes of DIY popular music preservation of which the places of our research are also a part.

A further acknowledgement of the contribution that 'informal' archives can make to the public record can be found in recent work by Alan McKee who, in arguing for the importance of archives to academic research about television's history, provocatively suggests that it might be material compiled by non-professional enthusiasts working outside the parameters of formal institutions that forms a more usable archive of television's content, partly because they are able to work without the constraints of institutional models (2011a; 2011b). While our institutions and their workers share many of the elements described by McKee, the DIY institutions we have encountered don't always fit the 'popular archive' model he outlines, specifically because, as we note above, many operate with a desire to meet the institutional criteria of formal archives and, for better or worse, may in doing so find themselves replicating the structures of formal institutions (and even more so in the event that they 'cross over' to become formal archives).

Like television, popular music has innumerable enthusiasts and connoisseurs, and in many ways the popular music collector or amateur archivist might be seen as the quintessential figure of popular expertise and vernacular collecting. Historically, the audience of popular music has been encouraged to amass material artefacts produced by the popular music industry and associated industries as an integral part of its ideology of consumption. It is no wonder, then, that some of the most comprehensive 
collections of popular music in recorded form and associated artefacts and ephemera are in private hands (see Milano, 2003; Huber 2010). What the emergence of DIY institutions (and to some extent McKee's popular archives) suggests in this context, however, is that there is a desire among some enthusiasts to create institutions that house these collections in ways that are open to the public or at least with broad public benefit in mind. One such enthusiast we have encountered is a Tel Aviv-based collector of Israeli vinyl who aspires to make his private collection public. He explained the reasons behind this desire: "All the information has to be in one place. One of my dreams... [is] to build a museum for the Israeli music. So you come to the place and you know everything that is published there. ... To concentrate all the information" (interview, 10 August 2011). Here, this collector is suggesting the utility of an institutionalised and public home for collections of popular music artefacts; a public site like a museum or an archive is appealing because it is a place with the potential to house the 'completeness' of history "in one place", even if this completeness is an impossibility, or only an imagined goal.

So, in calling the archives and museums explored in our work 'DIY institutions', our intention is to connect to and draw on some of the ways in which these other kinds of more informal, community or activist archives have been defined, but in an expansive way that best fits the popular music heritage framework under our consideration. In other words, an 'interest in music' and/or an 'interest in preserving music's material culture' in our examples doesn't (always) equate with an ethos of activism, or even Zinn's (1970/1997) call for 'the people' to document their own history in archival form. Rather the emphasis here links more closely to an ethos of getting on with it, taking 
initiative and, quite simply, doing it yourself. Like the archiving projects of Flinn's research, the agendas of the institutions under examination have their basis in the community; moreover, the parameters of these DIY collections are determined by the volunteers and emerge from within their own expertise. However, this is complicated by the fact that we have found in some cases that community emerges from within the archive itself, rather than being only a reflection or outcome of something that pre-exists its foundation. So although we don't mark them as necessarily 'activist', these communities of volunteers and enthusiasts who assemble around a shared interest in popular music and/or its heritage and labour in the DIY institution are equally 'able to strategically represent themselves rather than submitting their archives to be filtered through the words and space of state-based institutions' (Moore \& Pell, 2010: 261).

\section{Towards a Typology of sorts}

Based on research visits to a number of DIY institutions, all of them physical archives (some with a museum component) across a number of countries -- Australia, Austria, Iceland, the Netherlands, and the USA -- we are beginning to imagine three

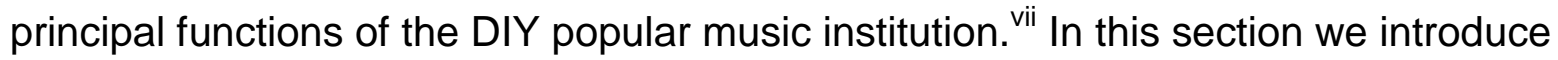
these functions -- cultural, social and affective -- in turn. These are structural functions which the institutions serve for their communities, and although we deal with each function separately, we acknowledge that they are intertwined, as we make clear below. It also is important to note that this is not an exhaustive list of the potential dimensions 
of these institutions; rather we highlight these particular elements because they figure prominently in each of the institutions under discussion.

\section{DIY institution as cultural institution}

The most obvious and familiar role of DIY institutions is a cultural one; they aim to serve as repositories for culture. This function connects them to other 'official' sites of cultural preservation, or 'memory institutions', like national museums and archives, which in some cases provide models which can be emulated or eschewed. While Tony Bennett's (1995) work, for example, has uncovered the complexity of the cultural function of museums, we want to think about the notion of 'cultural institution' in quite a simple way, in that these are organisations which set out to collect and document popular music culture in Raymond Williams's (1989) sense of its ordinariness; that is, popular music's appearance as sets of practices and experiences, commodities and material objects, which produce its place in a 'whole way of life'. In other words, these DIY places are less interested in creating a memorial canon of great works and artists (though they may of course contribute to this (see Baker \& Huber, forthcoming 2013)), but rather desire to archive a more 'complete' sense of popular music as it was lived and experienced.

The aim to document popular music culture manifests itself in a range of practices associated with collecting material artefacts, as illustrated in the example of Archiv Osterreichischer Popularmusik (also known as SRA), a non-profit archive of 
Austrian popular music located in Vienna. One of the archive's founders explained that the purpose of the SRA is as,

... a shelf where all culture is put. And what happens if somebody in a thousand years takes out this shelf - what will be ... there? ... So the next step was, its a very important thing of our culture, of our subculture as we defined it, to document ourselves. Not just to produce the music, but to document the culture so we don't forget it. (interview, 12 August 2010)

In this comment, we can see the connection drawn between preservation strategies, an institutional home, and cultural memory, where 'documentation' through the collection and safe-keeping of material artefacts in an institution is equated with securing their place in memory. This narrative imagines a person from the future revisiting his 'shelf of culture'; by being involved in assembling the material on this shelf, the archivist's role is that of memory-making agent, insuring a culture against forgetting. This impulse is an overwhelming one and drives the activities of many of these institutions. As the archivist from the ARChive admitted, "The only way I think you can preserve it is by keeping it" and although he was unsure what would happen to the artefacts in the future or how they would be used, his role is self-evidently one of keeping these items safe: "my job is to make sure to maintain it the best way it can be maintained" (interview, 21 October 2011).

Alongside the aims of assembling and maintaining a collection of cultural importance is the desired outcome of many DIY institutions to make these cultural 
artefacts publicly accessible. This aim again aligns many DIY places with the mission statements of national cultural institutions. Indeed, a number of the institutions have generated similar statements of purpose and list these goals on their websites and other promotional material. For example, the Victorian Jazz Archive (VJA) uses the words "[c]ollect, exhibit, preserve and store" to describe its foundational purpose in relation to Australian jazz, and its mission statement is: "Proactively Collecting, Archiving \& Disseminating Australian Jazz" viii However, in making this comparison to 'official' institutions' mission statements, we should point out that some of the people we spoke to emphasised that one of the limitations of official institutions are the restrictions placed on what is publicly accessible. Instead, many DIY places make accessibility a priority by finding ways to avoid onerous constraints on public access. Another of the founders of Austria's SRA made this quite overt when comparing the DIY archive she is involved with to the large-scale museums that dominate Vienna's cultural landscape: "But our purpose is, if we have the material we want to give the information, so we don't put it in a cellar, we want to use it, to give the information, put it in the database on the internet, to get it useable, and you can also burn CDs where its licensed, so you can use it. That's the aim, the purpose. We're not only archiving" (interview, 12 August 2010). These comments were in direct reference to a collection that the SRA had hoped to acquire but "we didn't have the money, it was expensive" (interview, 12 August 2010). Her co-founder added that this "highly interesting collection" was purchased by a major Viennese museum then "put in the cellar, they didn't even open it up, very rare early Austrian jazz things which I would be highly interested in" (interview, 12 August 2010). 
These comments suggest, at least in this case of the SRA, a series of different operational priorities in the DIY archive, where the specialist knowledge of fans and enthusiasts assesses objects, and tasks related to those objects, in ways that are not necessarily the same as those of a formal institution. In the narrative offered by the SRA's co-founders, for example, the rare jazz collection is relegated to the basement of the 'official' museum, but would have had pride of place and be publically accessible in the SRA. Recognising the importance of artefacts using different sets of parameters -ones which are generated from within the communities that organise themselves around these practices of cultural preservation -- are suggestive of an epistemological difference of note. As they outlined, these decisions are involved in the broader, yet more personal, task of representing, "our subculture as we defined it, to document ourselves" (interview, 12 August 2010). So while the DIY institutions have cultural functions that can be compared to those of 'official' institutions, these cultural functions are often articulated differently and, as we go on to argue below, are also connected to the ways in which these DIY places operate on the level of the social.

\section{DIY institution as social institution}

While the cultural function of a DIY institution is probably the purpose that aligns these places most closely with national or official archives and museums, the DIY institutions of our study diverge somewhat with the next element of our typology, in which we see these institutions forming themselves around functions related to sociality. Our observations in this area lead us to interpret these places as 'social institutions', 
where members of the workforce produce a collective identity around the enterprise of music preservation, but where individuals in that collective also find benefits and pleasures that are connected only by association to the tasks that are undertaken related to archiving and curation. In part we base this aspect of the typology on the work of Lave and Wenger (1991; Wenger 1998) whose term 'community of practice' captures the ways in which the execution of tasks associated with archiving and curation enable people to form social relationships with others who are similarly engaged. In Wenger's words, 'communities of practice are groups of people who share a concern or passion for something they do and learn how to do it better as they interact regularly' (2006: $n p) .{ }^{i x}$

In the case of our DIY institutions, we see community forming around the collective learning and enactment of tasks related to cultural preservation. Very few of the people we met had any formal training in curation, archiving or preservation, yet were on their way to becoming amateur experts in these fields. ${ }^{x}$ Sometimes this on-thejob education is assisted by episodic guidance from professionals at national institutions who are contacted regarding professional standards or specific issues related to preservation. However, generally speaking, the 'situated learning' (Lave, 1991) in DIY archives and museums is fostered within the community of practice with people working collectively to understand how best to go about the tasks at hand. This work therefore becomes very social, with the forging of relationships around skills acquisition. This sociality is not straightforward however, and we are cognisant of Ashley's caution that the application of Lave and Wenger's theory should not result in an 'idealized communitarian perspective' in which the emphasis on 'sharing' in the community of 
practice 'smoothes over difference and conflict' (2012: 189). Though we focus in this article on the positive aspects of sociality, elsewhere we have examined some of the more complex issues Ashley argues is missing from CoP approaches (Baker \& Huber, forthcoming).

Many of the archives and museums we have visited also include a social agenda which is not so connected to preservation tasks. Essentially this involves the creation of a warm and friendly environment which welcomes volunteers to participate in the institution's endeavours. This invitation to participate is also extended to those who don't possess specialist knowledge related to the music being preserved. This is, of course, not to suggest that there aren't elements of sociality in 'official' or national institutions but instead highlights that in the DIY institution sociality flourishes in ways that are rooted in the DIY ethos and a sense of 'collective collecting' at a community level. In other words, it is the grassroots, volunteer, not-for-profit aspects of these institutions which gives particular shape to the social elements we observed.

The primacy placed on the social dimension of these institutions can be read in the institutional spaces themselves. While there is rarely room to spare in these DIY facilities, and storage is a pressing issue, many of these institutions still make space for a kitchen or tea room where volunteers have an opportunity to socialise, and maintain the relationships they have developed through their volunteer work. We experienced this hospitality ourselves on a number of occasions, when we were urged to pause our interview schedules to join in lunchtime with the volunteers. In the small coastal town of Hoek van Holland in the Netherlands, for example, an interview had been arranged with 
the founder of Museum RockArt, which collects and displays items related to Dutch popular music history. However, the interview ended up including the core group of five volunteers who, in the hour before the museum opened, sat around a table outside the museum, basking in the autumn sun, eating, drinking, smoking, and laughing together. Their conviviality comes through strongly in the following interview extract:

Founder: Most important, the people. The volunteers are the most important part of the museum.

Volunteer 1: We are also old! [Laughter]

Volunteer 2: No! That's just her! [Laughter]

Sarah: How long have you all been volunteering here?

Volunteer 1: I've been volunteering over 7 years. Almost from the beginning.

Volunteer 3: For me, about 3 years.

Volunteer 2: Almost 2 years

Sarah (to Volunteer 1): So you've been here the longest. What brought you here to volunteer?

Volunteer 1: The music. And, well, we have the same friends, and I had no work. Sarah: And so you're here most days?

Volunteer 2: She came for one afternoon. [Laughter] Now she's here on Thursday, on Friday, if we were open on Sunday. [Laughter] Sarah: It really infects your enthusiasm!

Volunteer 1: Yes! That's true. (interview, 29 September 2011) 
On a previous visit to Museum RockArt, one of the volunteers had expressed that the presence of like-minded volunteers is an important drawcard for spending time there: "And that's the most fun part for me. Because I like to talk about music ..." (interview, 24 September 2011). So while the variety of tasks related to preservation and/or an interest in the music are certainly some of the reasons for volunteer participation, it is also the social atmosphere fostered in these places that leads volunteers to continue to gift their labour. For volunteers who are in their retirement, for instance, the personal connections that emerge around preservation tasks in these archives and museums have the power to enhance one's sense of purpose, especially when combined with the agency afforded by a DIY environment (Baker \& Huber, forthcoming).

These examples effectively illustrate that DIY institutions provide the context for a place that has something more than a cultural function; the importance attached to cultural preservation is not to be overlooked here, of course. However, what is interesting to us in these examples is the contribution that this social atmosphere offers to the enterprise of cultural preservation, and what this means for the ways in which communities feel connections to the material elements of music's historical past. For one volunteer at the VJA, this unquantifiable, social element of the archive is described in terms of the way the archive feels: "...it's added that social aspect that we didn't expect or look for, but it's been welcome ... it's a really warm atmosphere to work in" (interview, 19 July 2011). In other words, the 'social institution' is produced through relationships, creating an experience for volunteers (and visitors) that is not a tangible or quantifiable property of the institution and its aims, but is nevertheless essential to its sustainability and survival, as people work together, sometimes under difficult material 
circumstances, to achieve shared goals. This sense of 'warmth', then, feeds into the third element of our typology, which relates to the way that people feel in the institution, in terms of their relationships to each other, but also in terms of their relationships to the things that they are collecting and looking after.

\section{DIY institution as affective institution}

The affective dimension of DIY institutions is already evident in the above discussion of the enactment of social collectivity. However, the affective connectivity produced in these places is about more than the strong social bonds forged between volunteers. In the third part of our typology, then, we outline some of the instances we've observed in which feelings and emotions extend beyond connections between volunteers to include people's relationships to artefacts and music in ways that we think make these places 'affective institutions' as well as cultural and social ones.

'Love', for example, is a word that people often use to describe their relationship to music, and so necessarily appears in the narratives of some DIY institution founders as the impetus for their formation. As Museum RockArt's founder described, "I used my own funds to build this place. Now l'm very poor, but very happy. When you see the people inside, they have fun. That's what we do it for. To make people happy, to share the love of music. ... We don't do it for ourselves, we do it for the people" (interview, 29 September 2011). So one thing that the DIY institution offers is a series of everyday opportunities within the communities of practice for the affective connections between 
people and things to be performed; that is, DIY institutions are spaces of cultural preservation in which people can experience affective responses that are individual and, as we point to above, also collective.

The affectivity that we describe here is produced largely, though not entirely, by way of the volunteers' affective labour. Michael Hardt notes that early analyses of affective labour have traced how work that involves human contact and interaction, such as that which we observed in the DIY institutions, 'produce collective subjectivities, produce sociality, and ultimately produce society itself' (1999: 89). ${ }^{x i}$ In regards to the practices of volunteers, our interest is not with Hardt's emphasis on 'biopower' and 'capitalist accumulation', but rather with the liberatory potential of this form of labour through the affective atmosphere it creates. For the volunteers, and also the handful of paid workers we encountered, this mutual engagement in a co-operative labouring activity becomes a significant source of meaning in their lives.

The affect generated by volunteers' labour also radiates outwards, drawing visitors into its ambit. We found on a number of occasions that the workers in DIY institutions used accounts of visitor experiences as a way to negotiate their own feelings towards the institution and the work they do there, as well as their love of music. In describing interactions with visitors, volunteers end up articulating how deeply their own identity is tied to their work. This deep connection is well illustrated in the following extract from the interview with the founder of Tónlistarsafn Íslands, a music history museum located just out of Reykjavik, Iceland, which has a small room to display exhibits of Icelandic music: 
I'm excited to get up every morning to work, because there is ... always something new ... I don't think so much about if [my work is] appreciated ... I like the moment of when, what I call the 'wow' moment, when people experience things. ... I love to see that, when people are happy ... a few years ago we got a letter from a 16 year old boy ... his teacher told him to go into the [museum's online] databases and listen to old people say this poetry, these rhymes. And he did so, and he said 'I'm 16 years old, my grandmother died 20 years ago so I never met her. But here I met her.' He found her on our database. So this was a 'wow' moment. ... I mean this gives you the energy to go on ... (interview, 23 August 2010)

At the VJA in Australia, a very similar interaction is described by a long-term volunteer and the current secretary of the archive, who recounted an example of an encounter at the archive which "... makes the whole thing worthwhile" (interview, 26 June 2012). In this extract, the sense of excitement and wonder at the affective potentiality of the VJA is apparent:

...we had a girl last year -- she rang up and she said that her mother had died [and she was looking for information about her mother's brother]... And that she knew nothing except that her uncle had been a jazz musician -- would we have anything on him, so I said "yes"... So she said, could she come down and have a look? Well she came down within twenty minutes and we were able to show her pictures of him... and she was in tears, because she'd never seen a picture of 
this uncle... she was here for about four hours. And although we spent a lot of time doing it, it was really worth it to see the pleasure on her face... we feel it's a good job being satisfied by one person every now and again. (interview, 26 June 2012)

In these two examples which recount visitors' experiences at Tónlistarsafn Íslands and the VJA, the storytellers are also articulating their own connections to these places of cultural preservation, and so deploy these stories partly as a way of negotiating the affective investments they have in their DIY institutions, the music they love, and their roles in cultural preservation. These accounts bring to mind Lawrence Grossberg's (1992: 81) description of the role of affect in everyday life, in which he sees that, 'affect is what gives "color," "tone," or "texture" to the lived'. For Grossberg, "[a]ffect identifies the strength of the investment which anchors people in particular experiences, practices, identities, meanings and pleasures, but it also determines how invigorated people feel at any moment of their lives, their level of energy and passion' (82). So when the Icelandic museum's founder describes how he "love[s]" to see people happy because of his work, and when the VJA volunteer describes an emotional encounter that makes her feel like her work is "worthwhile", they are referring to these anchoring investments in two ways: firstly, in relation to recounting the visitor's experience of wonder ("'but here I met [my dead grandmother]"; "she'd never seen a picture of this uncle"), and secondly, in relation to the volunteer's experience of his/her own wonder in recognising the affective impact their endeavours can have on others ("this was a 'wow' moment"; "it was really worth it to see the pleasure on her face"). This double sense of wonderment is enabled by the collections held in these DIY institutions, and the 
materialised access volunteers and visitors have to the past through the sharing of memory stories.

Our observations of 'wonderment' link in interesting ways to Ross Gibson's (2006) meditation on the 'spirit house' of the museum, in which feelings of wonder and affection for objects permeate the experience of being in these spaces, and where, as a visitor, you might, '... feel the museum getting into you somehow... [and] sense a burgeoning responsibility for the material on display' (23.1). This resonates with volunteers also, whose activities, in being linked to Robert Stebbins' (1992) notion of 'serious leisure', are often described in the literature as a 'serious type of leisure visitor' (Ashley, 2012: 188). Gibson explores the 'somatic' responses to objects on display in the museum as part of their 'emotive force', and notes a growing 'care' for the items that affect the visitor at a bodily, perhaps irrational (or 'not entirely reasonable') level (Gibson, 2006: 23.2). These stories about what the museum 'does', expressed for instance in terms of the physical "energy" and emotional sustenance it gives its workers, is part of what keeps the people we interviewed going on the path of cultural preservation, despite the many obstacles DIY institutions face. This perhaps extends Gibson's notion of the spirit house's 'force field' $(2006,23.4)$ to include its reach to the volunteer and other workers in these DIY places, whose affective feelings and emotions are both key to the experience of (being in) the institution, and to what that experience can be for others.

These sensations come about in part because of the enactment of affective labour, but also because of the physical proximity to objects enabled in the museum 
space. In DIY institutions, physical closeness to objects in the collection is described by some of the volunteers as producing an environment that feels less like a stuffy institution, and more like a 'home', which Museum RockArt's founder, for instance, ties in to feelings of respect for the objects. As he explains here, the spatial arrangement of his museum is in part an attempt to create a comfortable place for things and people to be together:

Our idea is to make the museum more like a living room. It shows more respect. A combination of using the space, not too full, not too empty. ... presenting items by bringing it to the people, not standing behind glass, keep it closer to the people. Then it's not dusty. Traditional museums are thought of by people as dusty. That's what we try to fight. By making it more like a living room. (interview, 29 September 2011)

This proximity is both spatial -- in that the institutions enable physical closeness between people and things to be achieved in particular ways -- and also temporal -- in that the careful arrangement of the space itself produces opportunities for people to feel close to the historical past through physical proximity to the objects; or as Gibson poetically observes, 'how you're getting this sensation of a real, historical continuum folding into yourself, past into present, through these artefacts' (Gibson, 2006: 23.1).

The extent to which affect, proximity and objects are intertwined is further illustrated by another of Museum RockArt's volunteers. In this interview, the volunteer explained that, "Music is my big love, I'm a guitar player, and now I look after the guitars 
here" (interview, 24 September 2011). After the interview concluded and once the recorder was turned off, he expanded on his role as "the guitar man". He described how caring for the guitars in the museum's collection involved taking them home for restringing, a task that then gave him an opportunity to play the guitars. His philosophy: "instruments should be played, not just be on exhibit[ion]" (field notes, 24 September 2011). The thrill of proximity was evident in the enthusiastic and animated way that he spoke of his dealings with the many guitars on display. As a volunteer at Museum RockArt, this worker is in a position to deepen his connections to the genres, instruments and artists he has a passion for through exploiting the opportunity to work closely with guitars that he understands to be culturally significant. For the people we spoke to at a range of these DIY institutions, achieving nearness, or proximity, to the objects in the museum and archive represents one of the pleasures of the work they're involved in, and is in fact one of the benefits of working in these places (Baker \& Huber, forthcoming). We can think of DIY museums and archives, then, as places in which affect is produced and made possible through community and the process of remembering, and made again through encounters with objects that inspire both these things.

\section{DIY Futures for Popular Music Heritage}

What we have found during our research to date are groups of dedicated people who are very serious about making certain that a record of popular music's past is preserved for the future. These people are serious because they are worried about the 
fate of the vast array of material objects related to that history, and are anxious about them being lost if there is no place for them to go once their owners are no longer able to care for them. In this task, many of these volunteers see themselves as custodians of popular music's heritage. This concern to make a dedicated space for a materialised cultural memory of popular music has led these individuals and collectives to start their own institutions, and keep them operating in spite of difficulties with finding funding, appropriate premises for conservation, and enough volunteer hands to help the cause. In creating these institutions for cultural preservation, they also make places which operate in particular social and affective registers. These are some of the similarities between examples that are physically and generically disconnected that our research has exposed, and lead us to propose the beginnings of a typology of DIY institutions.

But like the collections in the archives and museums we have discussed here, this typology is incomplete and partial. We haven't covered all the cultural, social or affective aspects that have revealed themselves in our interview data, nor do we address other structural functions that we see as emerging in the ways DIY institutions serve their volunteers and the wider community. However, what this article points to are the potentialities of community-based interventions into the preservation and management of popular music heritage, and the ways in which the 'stuff' associated with popular music's cultures affects individuals. The enthusiasm of those labouring in the DIY institutions we have discussed in this article grows from a community-based desire to control the material history of popular music. It is also suggestive of what seems to be becoming a more general urge to collect -- indeed, collect collectively -that arises from within communities of consumption, and which, in the DIY context, 
involves retaining those collections in locations that are in close proximity to the people for whom the artefacts are (or are narrativised as being) most valued.

Moreover, as we write, we are continuing to discover more and more examples around the world that fit onto the spectrum of the typology we are developing in this article. These ongoing discoveries lend further support to our contention here that these tendencies are not isolated but widespread, that they produce institutions that are individual and specific but reside on a continuum of community-based heritage practice, that they have a history, and that they relate to an identifiable set of concerns making themselves public through the practices of communities and individuals wishing to participate in the management of music heritage. In writing this typology, and naming the 'DIY institution' we connect our observations to the work of others interested in the ways that cultural heritage is managed by 'ordinary people' (Flinn 2007; Flinn et al 2009), but we do so with the specificity of popular music heritage in mind (Collins 2012; Bennett 2009). What we discovered during our fieldwork is a set of commonalities that needed more precise articulation in order to understand adequately these DIY places and the motivations of their practitioners; while this typology is, as we note, a work in progress, it goes some way towards bringing together what we have found.

If popular music culture is, genuinely, a culture 'of the people', then its preservation in the hands 'of the people' seems appropriate. What this might mean for the development of cultural policy and funding streams that recognise the potentialities of DIY forms of institutionalised popular music preservation that run parallel to the national collecting projects of 'official' cultural institutions is a matter for future research. 
Yet if nothing else, our emerging typology of the DIY institution illustrates that these 'bottom-up', community-based preservation projects should be highlighting for policymakers the growing need to prioritise popular music heritage, particularly as its first mass audience--the baby boomers--approach old age, and an ever-increasing volume of popular music's material remnants needs to find a home.

\section{Acknowledgements}

The authors would like to thank the two anonymous reviewers for their helpful comments, and acknowledge the generous contributions of the DIY volunteers who took part in this research. 


\section{WORKS CITED}

Ashley, Susan L. T. (2012) 'Museum volunteers: between precarious labour and democratic knowledge community', in J. Paquette (ed.) Cultural Policy, Work and Identity: the creation, renewal and negotiation of professional subjectivities, pp. 187201. Farnham: Ashgate.

Baker, Sarah \& Alison Huber (forthcoming) "“Masters of our own destiny”: cultures of preservation at the Victorian Jazz Archive in Melbourne, Australia'. unpublished article (under review).

Baker, Sarah \& Alison Huber (forthcoming 2013) 'Locating the canon in Tamworth: historical narratives, cultural memory and Australia's "Country Music Capital”, Popular Music 32(2).

Bennett, Andy (2009) “"Heritage rock”: rock music, representation and heritage discourse', Poetics 37: 474-489.

Bennett, Tony (1995) The Birth of the Museum: history, theory, politics. London \& New York: Routledge. 
Collins, Jez (2012) 'Multiple voices, multiple memories: Public history-making and activist archivism in online popular music archives'. Unpublished MA Thesis. School of Media: Birmingham City University.

Collins, Jez \& Paul Long (forthcoming) 'Online Archival Practice and Virtual Sites of Musical Memory' in S. Cohen et al (eds) Sites of Popular Music Heritage: memories, histories, places. London: Routledge.

Dale, Pete (2008) 'It Was Easy, It Was Cheap, So What?: reconsidering the DIY principle of punk and indie music', Popular Music History 3(2): 171-193.

Fisher, Trevor (1957) 'The British Institute of Recorded Sound'. Tempo. 45 (September): 24-27.

Flinn, Andrew (2007) 'Community Histories, Community Archives: some opportunities and challenges', Journal of the Society of Archivists 28(2): 151-176.

Flinn, Andrew (2010) 'Independent community archives and community-generated content: "writing, saving and sharing our histories"', Convergence 16(1): 39-51.

Flinn, Andrew, Stevens, Mary and Shepherd, Elizabeth (2009) 'Whose Memories, Whose Archives? Independent community archives, autonomy and the mainstream', Archival Science 9: 71-86. 
Gibson, Ross (2006) 'Spirit House'. in C. Healy \& A. Whitcomb (eds)

South Pacific Museums: experiments in culture, pp. 23.1-23.6. Melbourne: Monash University ePress. DOI: 10.2104/spm06023.

Grossberg, Lawrence (1992) We Gotta Get Out Of This Place: popular conservatism and postmodern culture. New York: Routledge.

Hardt, Michael (1999) 'Affective labour', boundary 2. 26(2): 89-100.

Hesmondhalgh, David \& Sarah Baker (2011) Creative Labour: Media Work in Three Cultural Industries. Routledge.

Huber, Alison (2010) 'Making Time Stand Still: how to "fix" the transient Top 40'. International Journal of Cultural Studies. 13 (2): 147-162.

Huvila, Isto (2008) ‘Participatory Archive: towards decentralised curation, radical user orientation, and broader contextualisation of records management', Archival Science 8: 15-36.

Kelly, Lynda, Cook, Carolyn and Gordon, Phil (2006) ‘Building Relationships through Communities of Practice: museums and indigenous people', Curator 49(2): 217-234. 
Lave, Jean (1991) 'Situating learning in communities of practice', in L.B. Resnick, J.M. Levine and S.D. Teasley (eds) Perspectives on Socially Shared Cognition, pp. 63-82. Washington DC: American Pyschological Association.

Lave, Jean and Wenger, Etienne (1991) Situated Learning. Cambridge: Cambridge University Press.

Leadbeater, Charles \& Miller, Paul (2004) The Pro-Am Revolution: how enthusiasts are changing our economy and society. London: Demos.

http://www.demos.co.uk/publications//proameconomy

McKay, George (ed.) (1998) DiY Culture: party and protest in nineties Britain. London \& New York: Verso.

McKee, Alan (2011a) 'YouTube versus the National Film and Sound Archive: which is the more useful resource for historians of Australian television?', Television and New Media 12(2): 154-173.

McKee, Alan (2011b) 'Alternative Primary Sources for Studying Australian Television History: an annotated list of online Pro-Am collections', Screening the Past 32. http://www.screeningthepast.com/2011/11/alternative-primary-sources-for-studyingaustralian- television-history-an-annotated-list-of-online-pro-am-collections/ 
Milano, Brett (2003) Vinyl Junkies: adventures in record collecting. New York: St. Martin's Griffin.

Moore, Shaunna \& Pell, Susan (2010) 'Autonomous Archives', International Journal of Heritage Studies 16(4-5): 255-268.

Stebbins, Robert A. (1992) Amateurs, Professionals and Serious Leisure. Montreal: McGill University Press.

Stevens, Mary, Flinn, Andrew and Shepherd, Elizabeth (2010) 'New frameworks for community engagement in the archive sector: from handing over to handing on', International Journal of Heritage Studies 16(1-2): 59-76.

Strachan, Robert (2007) 'Micro-independent Record Labels in the UK: discourse, DIY cultural production and the music industry', European Journal of Cultural Studies 10(2): 245-265.

Tsai, Yi-Chun (2009) 'Cultivating the culture of museum volunteer learning - the approach of communities of practice', in W. Gieseke, S. Robak and M-L. Wu (eds) Transkulturelle Perspektiven auf Kulturen des Lernens, pp. 189-214. Bielefeld: Transcript.

Wenger, Etienne (1998) Communities of Practice. Cambridge: Cambridge University Press. 
Wenger, Etienne (2006) 'Communities of Practice: a brief introduction'.

http://www.ewenger.com/theory

Williams, Raymond (1989) Resources of Hope: Culture, Democracy, Socialism, R. Gale (ed.). London: Verso.

Withers, Deborah (forthcoming) 'Vulnerable Objects: the M=music of the Women's Liberation Movement' in S. Cohen et al (eds) Sites of Popular Music Heritage: memories, histories, places. London: Routledge.

'Why the ARC'. (n.d.) http://www.arcmusic.org/begin.html accessed Thursday 3 May 2012, 12.08pm.

Zinn, Howard (1970/1997) 'Secrecy, Archives and the Public Interest' in The Zinn Reader: writings on disobedience and democracy, pp. 516-528. New York: Seven Stories Press.

\footnotetext{
i The broader project is called Popular music and cultural memory: localised popular music histories and their significance for national music industries, funded under the Australian Research Council's (ARC) Discovery Project scheme for three years (2010-12, DP1092910). Chief Investigators on the project were Andy Bennett (Griffith University), Shane Homan (Monash University), Sarah Baker (Griffith University) and Peter Doyle (Macquarie University), with Research Fellow Alison Huber (Griffith University). Additional funding for fieldwork in Austria and Iceland was provided by an Australian Academy of the Humanities ISL-HCA International Research Fellowship (2nd Round, 2010) awarded to Sarah Baker. Since writing this article, the authors' work on DIY institutions has attracted further funding from the ARC, with the success of a second Discovery Project grant application: Do-it-yourself popular music archives: an international comparative study of volunteer-run institutions that preserve popular music's material culture (2013-15, DP130100317).

ii For example, the British Library Sound Archive, the UK's national institution for collecting popular music recordings and artefacts, began its life in the 1950s as the British Institute of Recorded Sound. Founded
} 
by a private individual (Patrick Saul) with financial support from a charitable trust and donations from the public and recording companies, this DIY institution became part of the British Library in the 1980s. In an early account of the Institute's DIY roots, Trevor Fisher notes: 'Realising what unique records there have been and how many of them have been lost makes it the more regrettable that this country, so eminent in the field of recording, has not in good time founded an Institute. Even now it might exist only as an idea if it had not been for the enterprise and generosity of a group of distinguished enthusiasts and critics, backed by a few leading musicians' (1957: 26). This comment encapsulates the spirit of the do-it-yourself ethos we investigate here.

iii We should point out that we make no claim on 'discovering' these DIY institutions, nor are we suggesting that they and the work they represent are a new phenomenon (indeed, as we note in n.2, these practices have historical roots, and stretch back as far as the 1800s (see Fisher, 1957 for more examples)). Rather, we seek to understand these institutions together, drawing examples from disparate places, in order to find their commonalities and therefore establish the ways in which they might speak to broader trends in cultural heritage.

iv The institutions we discuss in this article are: ARChive, New York City, USA; Archiv Osterreichischer Popularmusik (SRA) [Archive of Austrian Popular Music], Vienna, Austria; Tónlistarsafn Íslands [Icelandic Music History Museum], Kópavogur, Iceland; Museum RockArt, Hoek van Holland, the Netherlands; Victorian Jazz Archive (VJA), Melbourne, Australia. We also draw on an interview with an Israeli collector in Tel Aviv seeking to make his collection publicly accessible.

${ }^{\vee}$ For examples of writing related to music's DIY ethos, see McKay (ed. 1998); Strachan (2007); Dale (2008).

vi $\mathrm{http}: / /$ birminghammusicarchive.com/

vii While our examples here are limited to physical archives that collect material objects, we are aware of the growing cohort of online archivists (eg, Collins, 2012; Collins \& Long, forthcoming; Withers, forthcoming). We do not address the specificity of these archival practices here, but these virtual archives are part of the broader imagining of this project, and will be the subject of further research. The typology we explore here is intended to include such archives, though its parameters will necessarily be articulated differently in online-only institutions.

viii http://vicjazzarchive.org.au/1aboutvga\%20copy.htm

${ }^{i x}$ This idea has been used elsewhere in museum and volunteering literature as a way to understand cultural work that is bound by mutual interest in specific domains (see Kelly, Cook \& Gordon, 2006; Tsai, 2009).

${ }^{x}$ Another way of interpreting the work of volunteers in these places is alongside literature that outlines the rise of the 'professional amateur' (or 'amateur professional'), often referred to as 'Pro-Ams'. Leadbeater and Miller's report on the 'Pro-Am Revolution' (2004) noted the increasing cultural importance of amateurs who acquire skills that approach those of professionals. However, we connect these DIY institutions to this broad trend with the caveat that many of the people involved in running the institutions we investigate did not necessarily begin with the intention of becoming professional amateurs.

${ }^{x i}$ For a discussion of emotional and affective labour see Hesmondhalgh \& Baker (2011). 